\title{
Initial thoughts on Greene's the tragedy of commonsense morality
}

\author{
Ho Manh Tung \\ Ritsumeikan Asia Pacific University \\ Beppu, Oita, Japan
}

September 5, 2020

In his 2013 book, "Moral Tribes: Emotion, Reason, and the Gap between Us and Them," Joshua Greene ${ }^{1}$ contemplates two tragedies. The first is the tragedy of the commons, a wellstudied problem in the game theory and psychology literature. Here, if people are truly selfinterested, cooperation cannot arise, and everyone will use the commons until it is depleted. This problem is succinctly called the "Me vs. Us" problem. The second is the tragedy of the commonsense morality, which Greene named, refers to the problem of cooperation among groups, the "Us vs. Them" problem.

Greene argues evolution has equipped us with the mental tools (our emotions, the ability to infer ingroup vs. outgroup, etc.) to solve the "Me vs. Us" problem. Still, it did not give us the same resource to solve for the inter-group conflicts, given that each group often has a different set of moral norms, intuitions, and sacred values. Based on the new empirical sciences of how people form moral intuitions and make a moral judgment, Greene argues that to solve this problem, we must rely on a "deep pragmatism," a form of universal utilitarianism, where we should make moral decision to maximize the happiness of everyone and everyone has an impartial claim on happiness.

I think in the tragedy of commonsense morality, I think Greene has overemphasized three things: the role of biological evolution, the role of the group, and the role of the new empirical 
sciences of the mind (neuroscience, cognitive science, game theory, economics, etc.) in the process of moral negotiation.

First, when it comes to evolution, the question over whether groups or individuals are the basic units of evolution is often invoked whenever the issue of the group arises (see Robert Sapolsky's 2017 book, Behave's chapter $10^{3}$ ). So, I wonder what happens in the mind of each individual who encounters people in other cultures who need to decide whether to act out their own norms or to comply with the norms of others. I believe the same moral tools that evolution equips us to cooperate in the case of the tragedy of the commons, i.e., reason, calculation, empathy, compassion, must be utilized. Thus, the claim that evolution has not prepared us for the "Us vs. Them" problem is misguided.

Then, throughout history, people have always adopted and mixed values and create a new value system. This process has been explored extensively in the domain of cultural studies ${ }^{3,4}$ and management ${ }^{5}$. Perhaps, the discussion of how moral judgment and intuition are formed can benefit from the new developments of concepts such as cultural addivity ${ }^{3,4}$ and global mindsponge ${ }^{5}$. I guess Greene might be over-optimistic that the new empirical sciences of the mind will answer all the moral questions. Surely, truly hard data from experiments can tell us a lot about human minds. Still, without a deep appreciation of cultural nuances from the researchers, one can always question whether the hard data are really hard after all.

Later, in the 2007 paper in Science Magazine, Scott Atran, Robert Axelrod, and Richard Davis have eloquently argued for the importance of acknowledging the opposition's sacred values through symbolic concessions in conflict resolution6. Perhaps these kinds of conflicts over sacred values are in Greene's mind when he writes his book. Yet, these conflicts are on the extreme end of cultural conflict, and it is important to acknowledge that solving these conflicts are as important as they are extreme. Nowadays, in the globalized world, every day, we have a multitude of lower-grade cultural conflicts that take place and get solved in both the physical and digital places.

I believe a more mature science of the mind will need to take into account these everyday actions. 
Perhaps, the subsequent research themes can be put as "studying the triumph of commonsense morality is as important as understanding its tragedy." Its manifestations can be diverse and vivid such as "tragedy of errors" 7 or "reinforcing self-correction mechanism" 8 .

After all, these themes, in combination with Greene's morality discourse, will likely advocate Alberts et al. 's arguments for science and its values ${ }^{9}$ in the course of development for the humankind.

\section{References}

1. Greene, J. D. (2013). Moral tribes: Emotion, reason, and the gap between us and them. Penguin, New York.

2. Sapolsky, R. M. (2017). Behave: The biology of humans at our best and worst. Penguin, New York.

3. Vuong, Q. H., Ho, M. T., Nguyen, H. K. T., et al. (2020). On how religions could accidentally incite lies and violence: Folktales as a cultural transmitter. Palgrave Communications, 6(1), 82.

4. Vuong, Q. H., Bui, Q. K., La, V. P., et al. (2018). Cultural additivity: behavioural insights from the interaction of Confucianism, Buddhism and Taoism in folktales. Palgrave Communications, 4(1), 143.

5. Vuong, Q. H. (2016) Global mindset as the integration of emerging socio-cultural values through mindsponge processes: A transition economy perspective. In J. Kuada (ed.) Global Mindsets: Exploration and Perspectives (pp. 109-126). Routledge, UK.

6. Atran, S., Axelrod, R., \& Davis, R. (2007). Sacred barriers to conflict resolution. Science, 317, 1039-1040.

7. Allison, D. B., Brown, A. W., George, B. J., \& Kaiser, K. A. (2016). Reproducibility: A tragedy of errors. Nature, 530(7588), 27-29. 
8. Vuong, Q. H. (2020). Reform retractions to make them more transparent. Nature, 582(7811), 149.

9. Alberts, B., Cicerone, R. J., Fienberg, S. E., et al. (2015). Self-correction in science at work. Science, 348(6242), 1420-1422. 